\title{
Direito Penal e Modernização
}

AGERSON TABOSA PINTO

Doutor em Direito. Professor de Direito Romano na FA7. agerson@secrel.com.br

Sumário: 1) Introdução; 2) Direito penal antigo; 3) Direito penal clássico; 4) Considerações finais; 5) Referências bibliográficas; 6) Notas explicativas.

Palavra Chave: Direito romano. Direito penal. Modernização.

\section{INTRODUÇÃO}

A leitura do livro Da Divisão do Trabalho Social levou-me a refletir sobre se Durkheim, que figura entre os fundadores da Sociologia Jurídica, tinha razão quando defendeu, como evolução natural do Direito, aquela que vai do direito repressivo ao direito restitutivo. Para Durkheim, o Direito é o símbolo visível da solidariedade social. No direito penal, que trata de crimes e de penas, a sanção é sempre negativa, reprovativa ou repressiva, pois o crime representa a ruptura da solidariedade social, que é mecânica, pois baseada na similitude dos integrantes do grupo. No direito civil, que regula as relações contratuais e de cooperação, a função do direito é manter a interdependência, o equilíbrio, a harmonia da solidariedade que, no caso, é orgânica, pois fundada na diferenciação e na divisão do trabalho dos membros do grupo. A ser verdadeira essa tese, o direito penal teria precedido ao direito civil no sentido em que empregamos hoje as expressões? A tese de Durkheim teria aplicação no processo evolutivo do Direito Romano, ao longo do qual à proporção que a sociedade romana se diferenciava, o direito repressivo cedia espaço ao direito restitutivo? É o que esta comunicação pretende debater. Compreende ela duas partes, correspondentes aos dois períodos em que o Direito Penal romano será considerado, o antigo e o clássico. Começaremos cada uma delas com o referencial teórico, indispensável ao entendimento da doutrina durkheimiana, distinguindo sociedade simples de sociedade segmentaria, solidariedade mecânica ou por similitude, de solidariedade orgânica, ou por divisão do trabalho, direito repressivo de direito retributivo. Mostraremos, em seguida, 
na abordagem da primeira parte, algumas das características mais expressivas do direito penal antigo, entre as quais estão a religiosidade, o conservadorismo e o privativismo. Esse privativismo, como veremos, entra em choque, a todo instante, com o seu oposto, o coletivismo ou comunitarismo. Na sociedade atrasada, o crime, como conduta desviada, é ofensa do delinqüente não só à vitima mas também à sua comunidade e a sanção, através da pena, é vingança, não somente da vítima mas de todo o seu grupo. A administração da justiça criminal foi também, por muito tempo, comunitária, pois os julgamentos eram confiados às assembléias comiciais, as mesmas que detinham o poder de votar as leis, mas, a justiça civil, muito ainda ficou a cargo de particulares, deste as citações aos réus até a execução das sentenças.

Mostraremos, por fim, encerrando a primeira parte, que a Lei das XII Tábuas, embora localizada ainda no período arcaico, pois é de 450 a. C, representa, na verdade, uma codificação bastante avançada. Na segunda parte, após apontarmos algumas mudanças modernizadoras da sociedade romana, vamos destacar atributos do seu direito compatíveis com essa modernização, com realce para a secularização e a publicização das normas jurídicas. Esse avanço continua com a transição do delito privado ou ilícito penal para o ato ilícito ou ilícito civil. A obra, que inspirou este trabalho, foi o primeiro dos mais importantes livros de Durkheim, escrito em 1893, como tese de doutorado. Embora sem formação jurídica (era um filósofo que começou a vida profissional ensinando Sociologia), Durkheim ocupou-se do Direito para explicar os diferentes tipos de solidariedade social. É natural que tenha provocado reações negativas, partindo principalmente de juristas, como ocorreu, dois anos depois, em 1895, com a publicação de As Regras do Método Sociológico. Nessa obra, teria pregado, como princípio metodológico, a coisificação dos fatos sociais, entre os quais estava o direito, e teria defendido a normalidade do crime, como fato social. O que não se pode é deixar de reconhecer o mérito do livro em debate, pelas mais diferentes razões. Desde a importância do tema, a vastidão da pesquisa, a clareza dos argumentos até o cuidado metodológico e a rica bibliografia. $\mathrm{O}$ assunto se liga à genética do Direito, área de sua predileção ${ }^{(1)}$. Sua pesquisa foi submetida ao método histórico-comparado, orientado pela mudança evolucionista de Spencer, sua bibliografia contou com os livros dos autores de mais prestígio intelectual na época ${ }^{(2)}$.

\section{- Direito Penal Antigo}

Durkheim tentou responder àquelas duas perguntas básicas formuladas na introdução, com sua teoria da solidariedade social. Para explicar essa solidariedade, que, segundo ele, é uma realidade de natureza moral, valeu-se da funcionalidade do seu símbolo visível, que é o direito. Este, nas sociedades primitivas, revela-se 
de forma repressiva, produzindo a solidariedade mecânica, e, de forma restitutiva, nas sociedades mais evoluídas, gerando solidariedade orgânica ${ }^{(3)}$.

\subsection{Solidariedade Mecânica e Direito Repressivo}

A palavra solidariedade vem do latim - solidum - que significa inteiro. Solidariedade social ou grupal é a consciência que cada indivíduo tem de que integra a unidade grupal. A consciência, verbi gratia, que têm os filhos de integrarem, com os pais, o grupo família; que têm os alunos de integrarem, com os professores e funcionários, o grupo escola; que têm os cidadãos de integrarem, com os governantes, o grupo Estado. Quanto mais viva for essa consciência, mais solidário e coeso é o grupo. O direito, como "regra de conduta sancionada", ${ }^{(4)}$ tem por função a manutenção dessa solidariedade. Por isso ele é o seu símbolo visível. A solidariedade da sociedade simples, primitiva, homogênea, Durkheim chamou-a de mecânica, porque natural, espontânea, informal, inconscente. ${ }^{(5)}$ A indiferenciação funcional torna os indivíduos, dentro do grupo, semelhantes. Aderem eles totalmente ao grupo, perdendo como que sua individualidade, ou sua personalidade. A padronização do comportamento é reflexo dessa homogeneidade, que faz o direito manifestar-se sempre em forma de costume, e confunde o direito humano (jus) com o direito divino (fas). Por isso, a norma jurídica era santa, ela precisava de sanção ${ }^{(6)}$. Quando alguém comete um crime, além do prejuízo causado à vítima, transgride uma norma jurídica, “melindra os sentimentos que se encontram em todas as consciências sadias do mesmo tipo social”(7) e provoca até a ira dos deuses. A harmonia do grupo, afetada pelo crime, tem ligação com a pax deorum, daí porque a repressão não se faz esperar. As penas, instrumentos dessa repressão, primam pela severidade, sem que sua intensidade corresponda sempre à gravidade do malefício ${ }^{(8)}$

\subsection{Religiosidade e Conservadorismo}

Fustel de Coulanges chegou a dizer que o verdadeiro legislador dos antigos não foi o homem, mas a crença religiosa que acalentou em seu peito e a que obedeceu $^{(9)}$ Durkheim, a seu turno, afirma que, nas sociedades inferiores, o direito é quase exclusivamente penal, por isso é sobremodo estacionário, sempre repressivo e essencialmente conservador. "Essa fixidez do direito penal atesta a força de resistência dos sentimentos coletivos a que corresponde. Inversamente, a maior plasticidade das regras puramente morais e a rapidez relativa de sua evolução demonstram a menor energia dos sentimentos que são sua base: ou eles são mais recentemente adquiridos e ainda não têm tempo de penetrar profundamente nas consciência, ou estão se arraigando e sobem do fundo para a 
superfície”. ${ }^{10)}$ Quanto ao Direito Romano Antigo, ele não fugiu à regra. Como na história de todos os povos, a religião esteve também no berço da cultura romana, influindo em toda sua produção jurídica. "É que, no estágio primitivo da sociedade romana, correspondente, talvez, ao estado teológico da teoria da mudança social de Comte, era impossível delimitar as áreas específicas do fas e do jus. A religião, os deuses, as coisas sagradas eram do Estado, os sacerdotes eram como que funcionários públicos. Direito divino e direito humano se interpenetravam”. ${ }^{(11)}$ Note-se que o direito penal antigo manteve-se conservador, independentemente da redução de seu grau de religiosidade. "Compare-se o direito penal, tal como a Lei das XII Tábuas fixou-o em Roma, com o estado em que se encontra na época clássica, as mudanças que se podem constatar são pouquíssimas, se comparadas com as que o direito civil sofreu durante o mesmo tempo". ${ }^{(12)}$

\subsection{Comunitarismo Versus Privativismo}

A mistura, para não dizer o confronto, do comunitário com o privado, é uma constante em todas as sociedades antigas. Tal constatação é facilmente verificável no Direito. Bonfante chega a relacionar, entre as características do direito arcaico romano, o paralelismo entre o direito público e o direito privado, ${ }^{(13)}$ para o que Silvio Meira encontrara uma explicação, à luz dos princípios da Sociologia. "A família, na origem da sociedade romana, era um organismo com características políticas, com um pater, chefe civil e militar, sacerdote e magistrado ... Era uma unidade política, acastelada na domus, com seus deuses próprios e uma disciplina férrea. Com tal fisionomia, a família tornou-se o centro da vida privada romana e atraía para o seu âmbito normas, princípios e atribuições estatais. O pater, como sacerdote, aplicava o jus sacrum doméstico; como magistrado, julgava os que estavam sob seu poder ( potestas), como direito de vida e de morte ( jus vitae necisque). O direito público e o privado por vezes se confundiam, interdependiam, mal definidas que eram as fronteiras. Com a organização da civitas, a organização familiar passou a ter aspecto diferente, absorvida que foi gradativamente por aquela”. (14) Na verdade, somente quando essa absorção, da família pela civitas, se completou, é que o direito público começou a desenvolverse. Com relação ao Direito Penal, propriamente dito, Mommsen é muito claro e explícito ao afirmar que ele só passou a existir quando a repressão tornou-se completamente estatal. Tal só foi possível quando a lei: 1. Colocou limites ao arbítrio do juiz; 2. Relacionou os atos tidos como delitos; 3. Organizou o procedimento; 4. Determinou a reparação adequada ${ }^{(15)}$. E conclui: "De ahora en adelante no podia haber en Roma ningún delito sin previa ley criminal, ningún procedimiento sin previa ley procesal, ni ninguna pena sin previa ley penal”. ${ }^{(16)}$ Se tomarmos, como referência, a Lei das Tábuas, quando o direito penal já havia 
começado e já mostrava sinais de avanço, encontramos várias marcas do privativismo, a impedir a modernização da justiça criminal. Com efeito, na definição da pena, a lei decenviral ainda autorizava a vingança privada, não em sua forma primitiva e absoluta, mas condicionada à proporção da ofensa, conforme o princípio do talião. Autorizava igualmente, as composições, que são também manifestação de privativismo, pois oriundas do acordo das partes. Nelas, a determinação da pena não expressa somente vontade unilateral da vítima, mas também a do autor do maleficium. ${ }^{(17)}$. É fácil também identificar a presença do privativismo nos sistemas processuais, mais no civil do que no criminal. No processo civil, tanto no período da Legis Actiones, quanto no das fórmulas, a citação do réu era feita pelo autor. Ao particular, após o reconhecimento pelo magistrado do seu direito de acionar(jus actionis), cabia-lhe fazer a citação do réu, para que o processo pudesse deslanchar. O juiz ou árbitro era um particular, leigo, sem toga, um judex privatus, que podia ser escolhido por indicação das partes. Também no final do processo, a execução da sentença ficava a cargo da parte vencedora. Somente no terceiro sistema, o extradordinário, é que a publicização processual se completou. A citação era da alçada de serventuários da justiça, o judex era togado, oficial, e pela execução das sentenças se responsabilizava a própria administração da justiça. No processo criminal, a citação sempre foi publica, pois feita através de editos e a execução das sentenças era da competência de agentes do governo ${ }^{(18)}$.

\subsection{A LEI DAS XII TÁBUAS}

Como a sociedade romana proviera da junção de três tribos - Ramnes, Tities e Luceres - ela nunca foi tão homogênea ou simples quanto outras sociedades primitivas. Em conseqüência, o Direito Romano, mesmo o do período antigo, já se revelava bastante diferenciado, evoluído, modernizado. Prova eloqüente disto é a Lei das XII Tábuas, considerada por Santos Justo o primeiro marco da tendência romana de diferenciar os conceitos. ${ }^{(19)}$ Embora promulgada no período arcaico, a lei decenviral já se manifestava, para Durkheim, bastante avançada, pois: 1 . Era absolutamente laica $^{(20)} ; 2$. Continha todos os principais germes do nosso direito atual $^{(21)}$ e 3. Nela, o espaço do direito criminal era limitado e o direito cooperativo fazia sua aparição ${ }^{(22)}$

\section{\ Direito Penal Clássico}

Segundo a teoria neo-evolucionista de Durkheim, o que fez a transformação da sociedade romana arcaica rumo à modernização foi sua crescente diferenciação. Diferenciação de suas estruturas e funções, na linguagem funcionalista. ${ }^{(23)} \mathrm{E}$, com 
a sociedade, modernizou-se também o seu direito, e, mais especificamente, o seu direito penal. Examinemos, com Durkheim, esse fenômeno, observando o surgimento de novo tipo de solidariedade social, a solidariedade orgânica, com o progresso do direito restitutivo, e os processos de secularização e publicização do direito, e, por fim, acompanhando a transição dos delitos privados e quase-delitos para os atos ilícitos.

\subsection{Solidariedade Orgânica e Direito Restitutivo}

A sociedade homogênea primitiva, impulsionada pela diferenciação, começa a dividir-se em sociedades segmentárias. Em Roma, esse processo começou muito cedo. As três tribos do núcleo primitivo produziram, cada uma, 10 gentes, cada uma das quais originou 10 famílias. Assim, eram 300 famílias patriarcais, todas iguais, com dezenas e centenas de personae, quase todas iguais, alieni juris, pois só era sui juris quem não tivesse ascendente varão vivo. Era um só tipo de organização familiar com somente duas funções: a de chefia, do pater e a de subordinação, dos parentes. Ao lado da família patriarcal, havia a organização política da civitas monárquica, integrada pelos cives e chefiada pelo rex, que concentrava em suas mãos todas as funções governamentais. O exclusivismo ou particularismo, tanto do grupo familiar ${ }^{(24)}$, quanto da sociedade política ${ }^{(25)}$ era sinal de atraso, pois se opunha ao universalismo, variável caracterizadora de modernização ${ }^{(26)}$.

A existência destas duas realidades distintas - a família e o Estado - reguladas ambas por normas jurídicas, deve ter inspirado a Ulpiano aquela classificação bipartida ( duae positiones) do direito, ainda hoje utilizada. ${ }^{(27)}$ Será publicum jus aquele direito cujo interesse maior for do Estado ou do povo (quod ad statum rei Romanae spectat) e privatum jus, aquele que regular matéria de interesse prevalecente do particular (quod ad singulorum utilitatem). Essa dualidade deve ter inspirado também a Durkheim a concepção do direito repressivo e do direito restitutivo, embasando aquele a solidariedade mecânica, e este, a solidariedade orgânica. Para Durkheim, o direito restitutivo é aquele que "não implica necessariamente um sofrimento do agente” (como o direito repressivo), "mas consiste apenas na reparação das coisas, no restabelecimento das relações perturbadas sob sua forma normal, quer o ato incriminado seja reconduzido à força ao tipo de que desviou, quer seja anulado, isto é, privado de todo e qualquer valor social”. (28) Compreende ele "o direito civil, o direito comercial, o direito processual, o direito administrativo e constitucional, fazendo-se abstração das regras penais que se podem encontrar aí”. ${ }^{(29)}$ Como esse direito é próprio das sociedades diferenciadas, ele próprio se diferencia e “cria órgãos cada vez mais especiais: tribunais consulares, tribunais trabalhistas, tribunais administrativos de toda sorte. Mesmo em sua parte mais geral, a saber, o direito civil, ele só entra 
em exercício graças a funcionários particulares: magistrados, advogados, etc., que se tornaram aptos a esse papel graças a uma cultura toda especial”. ${ }^{(30)}$ A solidariedade social, simbolizada pelo direito cooperativo, "se assemelha, explica Durkheim, à que encontramos nos animais superiores. De fato, cada órgão aí tem sua fisionomia especial, sua autonomia, e contudo a unidade do organismo é tanto maior quanto mais acentuada essa individuação das partes. Devido a essa analogia, propomos chamar de orgânica a solidariedade devida à divisão do trabalho”. ${ }^{(31)}$ Por essa solidariedade, de fato, por um lado, cada um depende tanto mais estreitamente da sociedade, quanto mais dividido for o trabalho nela e, de outro, a atividade de cada um é tanto mais pessoal quanto mais for especializada”. (32) Ao examinarmos, em seguida, algumas características do direito clássico, é fácil mostrar a diferenciação por que passou a sociedade romana, implicando o declínio do direito repressivo e a evolução do direito restitutivo. É que a solidariedade, que mantém a coesão do grupo, não é mais predominantemente mecânica, decorrente da similitude dos indivíduos, mas, antes, é orgânica, calcada na diversidade de papeis, produzida pela divisão do trabalho.

\subsection{Secularização do Direito}

Já vimos que a laicização ou secularização é um dos primeiros sinais de modernização de um direito. Em Roma, nos tempos mais recuados, o direito e a religião faziam-se presentes em todo relacionamento humano. A própria norma era indiferenciada, não se distinguindo, nela, o aspecto divino do aspecto puramente humano. Os romanos, porém, não tardaram muito a distinguir o jus do fas, o direito ordenado (jubere) pelo homem para o homem do direito falado (fari) pelos deuses para as criaturas humanas. ${ }^{(33)}$ É que as coisas sagradas, os sacerdotes continuavam sendo objeto do direito público, pois o Estado mantinha sua religião oficial, mas sem a importância que tinham os magistrados, responsáveis pela administração da cívitas. ${ }^{(34)}$ A família patriarcal começa a diferenciar-se. Os parentes provinham de dois tipos de parentesco: o agnatício (agnatio) e o cognatício ou consangüíneo (cognatio). O patermfamilias tinha, sob seu poder, não só os filhos, mas pessoas diferentes: clientes, escravos e, mais tarde, colonos. De vários modos, podia operarse a conventio in manum: a confarreatio, a coemptio e o usus.

A atividade econômica básica - a agricultura - começou também sua diferenciação. Ao lado da agricultura familiar de subsistência, surgiu a agricultura a comercial de exportação interna e internacional. Para exportar os excedentes agrícolas e as primeiras manufaturas industrializadas, era necessária a criação de um direito novo, o jus gentium. O direito começa, então, a também diferenciarse. A expansão da agricultura e da indústria provoca o setor serviços e a economia 
moderniza-se ainda mais, ao impulso da divisão do trabalho ${ }^{(35)}$. Surgem as pessoas jurídicas, tanto as constituídas de pessoas físicas (universitates personarum) quanto às constituídas de coisas (universitates rerum), para atendimento de interesses os mais diferentes, entre os quais os interesses profissionais, e, com elas, vai progredir o direito restitutivo. $\mathrm{O}$ formalismo e o exclusivismo do antigo jus civile vão ser quebrados pelo jus edicendi dos magistrados e pelo jus respondendi dos jurisconsultos. Assim, do jus honorarium e da jurisprudentia vai surgir um direito civil novo. Com a República, também a civitas vai diferenciar-se. As tarefas do governo começaram a definir-se com mais clareza. O Executivo, sob o comando dos magistrados, agora é plural e não mais monocrático, como na Realeza. A princípio, eram apenas dois cônsules, mas, depois, sempre que a divisão do trabalho exigia, eram criadas outras magistraturas. A especialização crescente e a internacionalização das relações sociais explicavam, por exemplo, o surgimento do pretor peregrino, ao lado do pretor urbano. No Legislativo, estavam os comícios, inicialmente somente por cúrias, agora também por centúrias e tribos, votando as leis, e o senado, com sua auctoritas, como que as sancionando. O Judiciário, que, como queria Kelsen, com certa razão, sempre exerceu uma função executiva, a de administrar a justiça, sempre esteve, por isso, atrelado ao Executivo. A jurisdictio (o poder de dizer o direito) e a coercitio (o poder de punir) sempre estiveram com os magistrados, encarregados também da função executiva geral de governar ou administrar (gérere personam civitatis) ${ }^{(36)}$. Mas o Judiciário romano vai também especializar-se, acompanhando, pari passu, a evolução do próprio direito e do próprio Estado.

\subsection{A Publicização do Direito}

No âmbito da família, as faltas, os desvios de conduta não eram delitos, mas eram julgados pelo consilium domesticum para a punição dos faltosos. Não se podia, porém, falar em direito penal, pois a norma violada era de natureza moral. Poderia haver repressão do grupo à conduta desviada, mas de maneira difusa e inorganizada. A pena, aplicada ao delinqüente, porque jurídica, é específica e organizada. Com o desenvolvimento da civitas, esta, como já vimos, absorveu a família, extinguindo o direito doméstico. As fases da vingança privada e das composições entre as partes foram superadas. Doravante, o delito e a pena precisam ser previstos em lei, para que sejam tidos como tais, e a identificação, o reconhecimento do crime e sua repressão devem ser feitos pelo Estado. É o que diz Silvio Meira: “A pouco e pouco o Estado foi ampliando o seu círculo de ação, atraindo para o seu campo o direito penal. A Justiça privada foi substituída lentamente pela Justiça pública”(37). Também o direito processual penal e civil foi publicizado quando suas regras passaram a constar de leis e quando todos os atos, 
já referidos, da competência privada, passaram para a responsabilidade do poder judiciário. ${ }^{(38)}$

\subsection{Do Delito Privado ao Ato Ilícito}

Vamos, por último, mostrar, estudando a evolução do Direito Romano, a transição do delito privado, de sanção repressiva, para o ato ilícito, de sanção restitutiva, fenômeno favorável à tese de Durkheim, em debate. Diz ele: "O delito privado do direito romano representa uma espécie de intermediário entre o crime propriamente dito e a lesão puramente civil. Ele possui traços de ambos e flutua entre os confins dos dois domínios. É um delito no sentido de que a sanção fixada pela lei não consiste simplesmente em restaurar as coisas; o delinqüente não é apenas obrigado a reparar o prejuízo que causou, mas deve algo mais, uma expiação. No entanto, não é exatamente um delito, pois se é a sociedade que pronuncia a pena, não é ela que deve aplicá-la. É um direito que ela confere à parte lesada, que é a única a dispor livremente dele»(39).

É o que observa também Silvio Meira, quando diz que o direito penal privado constitui o embrião de um capítulo do Direito Civil: o das obrigações. Observase uma interpenetração nos campos dos direitos penal e civil. Os delitos privados, com a evolução social, passaram a integrar o direito público, enquanto muitos institutos do direito civil ... Que, nas origens, eram de caráter público, passaram a ser incorporados ao direito privado". ${ }^{(40)}$ Os romanos não teorizaram sobre o ato ilícito, como também não o fizeram sobre o delito, ${ }^{(41)}$ mas, segundo César Rascón, "fue la jurisprudência la que interpretando la lex Aquilia, a partir de la idéia de la culpa, puso las bases de la noción de causalidad e imputabilidad, que preside los modernos ordenamientos en matéria de responsabilidad extracontratual”. ${ }^{(42)}$ Mas, o que é o ilícito civil ou ato ilícito e o que o faz diferente do delito privado ou ilícito penal? O critério para responder, ensina San Tiago Dantas, é puramente formal: "Foi esse ato descrito na lei penal como crime? O ilícito é penal. Não foi descrito, o ilícito é civil. ${ }^{(43)} \mathrm{E}$ prossegue: "o ato ilícito é a transgressão de um dever jurídico imposto pela lei”(44). A obrigação gerada pelo ilícito civil é extracontratual exatamente porque decorre de imposição da lei e não de acordo de vontades firmado nos contratos. Diz-se também responsabilidade aquiliana, por que prevista na Lex Aquilia, que regulamentou o delito privado intitulado damnum injuria datum. ${ }^{(45)}$ Até essa lei, promulgada por volta de 287 a.C., para alguém ser responsabilizado pelo referido delito, mister se fazia provar-lhe a intenção dolosa e provar também que o dano tivesse sido causado diretamente pelo agente. Observa San Tiago Dantas que, enquanto o Direito Penal, cada dia, se aferra mais à personalidade do agente para fazer realmente do agente não só o 
ponto de imputação do delito, como o ponto de imputação da pena, o Direito Civil, pelo contrário, tem um interesse capital em alargar a imputação da ilicitude ... Essa necessidade de dilatar a responsabilidade, além dos limites do agente do ato danoso, já os romanos o sentiam, embora não com a nitidez e com a flexibilidade da dogmática moderna, e, por isso, talvez, é que surgiu, no Direito Romano, aquela atormentada figura dos quasi-delicta. Não se sabe, ao certo, qual era o critério que os jurisconsultos romanos tomavam para considerar certas ações como delicta, outras, como quasi-delicta. Mas, o que parece mais certo, é que nos quasi-delicta iam principalmente os casos de responsabilidade indireta, os casos em que se queria responsabilizar, não o causador do malefício, mas alguém que estivesse por trás do causador do malefício”. (46) Por fim, ainda é San Tiago Dantas quem ensina: os códigos modernos que ainda utilizam, como o Código de Napoleão, a nomenclatura romana - delicta e quasi-delicta - na verdade já estão tratando do ato ilícito. “ Eles conservam os nomes: delitos e quase-delitos, mas em vez de conceituarem um número determinado de delitos dão um conceito genérico que já é, de algum modo, um conceito de ato ilícito.” (47) A partir da Lex Aquilia, a jurisprudência romana fixou os conceitos de culpa e dano, indispensáveis à correta interpretação do delito, chamado dano injustamente causado, e de sua lei regulamentadora, os quais chegaram até nós, inalteráveis, sendo utilizados na configuração do ato ilícito. Eis como o Código Civil da Espanha, em seu artigo 1.902 descreve o ato ilícito: “El que por acción o omisión causa daño a outro, interviniendo culpa o negligencia, está obligado a reparar el daño causado”. (48) O novo Código Civil Brasileiro, que é de 2002, ao dizer: “ Os bens do responsável pela ofensa ou violação do direito de outrem ficam sujeitos à reparação do dano causado” ... Parece destacar o elemento dano em detrimentos do elemento culpa. (49)

\section{Considerações Finais}

1. A conceituação de solidariedade, como característica do grupo social; a sua classificação em mecânica e orgânica; a caracterização e classificação do direito em repressivo e restitutivo, e o relacionamento entre solidariedade mecânica e direito repressivo, e solidariedade orgânica e direito redistributivo foram construções teóricas de Durkheim que o projetaram entre os maiores nomes não só da Sociologia Geral, mas também da Sociologia Jurídica.

2. A decisão de misturar Direito com Sociologia, nesta ponencia, partiu da convicção de que juristas e sociólogos devem andar e trabalhar juntos, de mãos dadas, em cooperação, pois os trabalhos de uns beneficiam, em verdade, os trabalhos dos outros. O conhecimento profundo do fato social deve ter favorecido a Durkheim os estudos e pesquisas sobre o crime, assim como a 
prática da Justiça Criminal favoreceu, por certo, a Gabriel Tarde, que era juiz, na elaboração de suas Leis da Imitação.

3. A sociedade primitiva, simples, homogênea, indiferenciada, se mantinha una, coesa, graças a uma consciência coletiva, fruto de sentimentos fortes que dominam a todos, abafando como que as consciências individuais. Por isso, nessa estrutura indiferenciada, os indivíduos eram todos iguais, como os anéis da minhoca, sem liberdade individual, sem personalidade. Assim, a norma, então existente, que era, ao mesmo tempo, moral, jurídica e religiosa, destinavase a manter a solidariedade, que era mecânica, porque natural, informal e instantânea, punindo os desvios de comportamento. Por isso, o direito primitivo, como também o Direito Romano, era predominantemente repressivo.

4. A Lei das XII Tábuas aparece como um divisor de águas. De um lado, um direito arcaico, consuetudinário, formalista, religioso e exclusivista, e, do outro, um direito que começa a modernizar-se, provindo da lex e de outras fontes, preferindo o conteúdo à forma, perdendo sua religiosidade e quebrando o seu exclusivismo.

5. Quando a sociedade romana começou a modernizar-se - com papéis, coletividades, normas, valores e sanções diferentes - a solidariedade garantidora de sua unidade, deixa de ser mecânica e se torna orgânica. O todo passou a depender mais das partes. O indivíduo, a autonomia da vontade, a personalidade, o status individual passaram a ser mais importantes. $\mathrm{O}$ direito, então, mais secularizado e mais publicizado, vai ser menos repressivo e mais restitutivo, passando as obrigações a jorrarem mais dos contratos do que dos delitos. Pacta sunt servanda.

6. Prosseguindo esse desenvolvimento, da repressão para a restituição, os juristas modernos descobriram no delito privado - damnum injuria datum - a semente do ilícito civil ou do ato ilícito, pela interpretação que os juristas romanos fizeram de sua lei regulamentadora, a Lex Aquilia. Não se trata de uma volta ao privativismo arcaico. Antes, porém, de mais uma prova em favor da tese de Durkheim, de que o Direito evolui, marchando da repressão para a restituição.

\section{REFERÊNCIAS BibliogrÁficAS}

BOGARDUS, Emory S. A Evolução do Pensamento Social. Rio de Janeiro: Fundo de Cultura, 1965.

BONFANTE, Pietro - Histoire du Droit Romain. Paris: Sirey, 1928.

BURDESE, Alberto. Manuale di Diritto Pubblico Romano, 2 2a ed., Torino: Utet, 1997. CARBONNNIER, Jean. Sociologia Jurídica. Coimbra: Almedina, 1979. COULANGES, Denis Fustel de. A Cidade Antiga. São Paulo: Hemus, 1975. 
CUVILLIER, Armand. Manual de Sociologia. 2ª . Ed., Buenos Aires: ElAteneo, 1959. DANTAS, San Tiago. Programa de Direito Civil. Rio de Janeiro: Editora Rio, 1979. DURKHEIM, Émile. Da Divisão do Trabalho Social. São Paulo: Martins Fontes, 1999.

DUVIGNAUD, Jean. Durkheim. Lisboa: Edições 70, 1982.

GAUDEMET, Jean. Institutions de l‘Antiquité. Paris: Sirey, 1982.

GIORDANI, Mário Curtis. Direito Penal Romano, 2a . Ed., Rio de Janeiro: Forense, 1987.

MATOS PEIXOTO, José Carlos. Curso de Direito Romano. Rio de Janeiro: Haddad, 1960.

MEIRA, Sílvio. Lei das XII Tábuas. 2a . Ed., Rio de Janeiro: Forense, 1961. . Processo Civil Romano 2a . Ed., Belém: Farângola, s/d.

MOMMSEN, Teodoro. Derecho Penal Romano. Pamplona, Navarra: Jimenez Gil Editor, 1999.

MOREIRA ALVES, José Carlos. Direito Romano, I. 5a. Ed ., Rio de Janeiro: Forense, 1983.

PARSONS, Talcott. Social System. New York: Maccmillan, 1968.

PINTO, Agerson Tabosa. Direito Romano. 2a ed., Fortaleza: FA7, 2003.

RASCÓN, César García. Manual de Derecho Romano, 2a . Ed . Madrid: Tecnos, 1999.

ROSTOVTZEFF, M.. História de Roma. 5a. Ed., Rio de Janeiro, Zahar, 1983.

SANTOS JUSTO, A. Direito Privado Romano, I, $2^{\text {a }}$. Ed. Coimbra: Coimbra Editora, 2003.

SMELSER, Neil J. (ed). Sociology: an introduction. New York: John Willey \& Sons, 1967.

\section{a Notas Explicativas}

1. Vide, em CARBONNIER, JEAN - Sociologia Jurídica (Sociologie Juridique), Coimbra, Almedina, 1979,p. 116, e em DUVIGNAUD, JEAN - Durkheim, (Durkheim), Lisboa, Edições 70, 1982, pp. 47-48, outros trabalhos de DURKHEIM, versando sobre temas jurídicos, principalmente de direito penal. 
2. Os dados secundários da pesquisa de DURKHEIM foram extraídos de clássicos, que vão deste Aristóteles, Platão, Sêneca, Plínio, Darwin, Laplace, Montesquieu, Stuart Mill e Adam Smith até Garofalo, Lombroso, Comte, Spencer, Tarde, Morgan, Accarias, Aléxis de Tocqueville e Fustel de Coulanges.

3. “A solidariedade social... É um fenômeno totalmente moral, que, por si, não se presta à observação exata, nem, sobretudo à medida. Para proceder tanto a essa classificação quanto a essa comparação, é necessário portanto substituir o fato interno que nos escapa por um fato externo que o simbolize e estudar o primeiro através do segundo. Esse símbolo visível é o direito”. DURKHEIM, ÉMILE - Da Divisão do Trabalho Social (De la Division du Travail Social), São Paulo, Martins Fontes, 1999, p. 31.

4. Idem, ibidem, p. 36

5. "Essa palavra não significa que ela a solidariedade seja produzida por meios mecânicos e de modo artificial. Só a denominamos assim por analogia com a coesão que une entre si os elementos dos corpos brutos, em oposição à que faz a unidade dos corpos vivos. O que acaba de justificar essa denominação é que o vínculo que une assim o indivíduo à sociedade é de todo análogo ao que liga a coisa à pessoa. A consciência individual, considerada sob esse aspecto, é uma simples dependência do tipo coletivo e segue todos os movimentos, como o objeto possuído segue aqueles que seu proprietário lhe imprime”. DURKHEIM, ÉMILE, op. Cit., p. 107.

6. " "La sanción es lo que consagra (del latin: sancire) la regla, lo que permite a esta permanecer sancta, es decir sagrada”. CUVILLIER, ARMAND - Manual de Sociologia (Manuel de Sociologie), 2a . Ed., Buenos Aires, El Ateneo, 1959, pp. 392 - 393.

7. DURKHEIM, ÉMILE, ibidem, p. 43. “... Um ato é criminoso quando ofende os estados fortes e definidos da consciência coletiva”. Idem, ibidem, p. 51.

8. "Em Roma o ladrão devia não apenas restituir o objeto roubado, mas pagar, além disso, uma multa equivalente ao duplo ou ao quádruplo do valor deste". DURKHEIM, ÉMILE, ibidem, p. 57.

9. FUSTEL DE COULANGES, DENIS - A Cidade Antiga (La Cité Antique), São Paulo, Hemus, 1975, pp. 11-23.

10. DURKHEIM, ÉMILE, ibidem, p. 48.

11. PINTO, AGERSON TABOSA - Direito Romano $2^{\mathrm{a}}$ ed., Fortaleza, FA7, 2003, pp. 43-44. “Assim BOGARDUS comentava esse primeiro estado da famosa lei de Comte: o raciocínio teológico conduz a uma organização militarista e monárquica, na qual figura Deus à testa da hierarquia, como rei dos reis e poderoso guerreiro, ao passo que os seres humanos são organizados através dos princípios militares. Reinaria a sanção divina. Embora expressada por líderes humanos, essa sanção não poderia ser questionada.” BOGARDUS, EMORY S. - A Evolução do Pensamento Social (The Development of 
Social Thought), Rio de Janeiro, Fundo de Cultura, 1965, $1^{\circ}$ vol., p. 233). In Pinto, Agerson Tabosa, op. Cit., p. 43.

12. DURKHEIM, ÉMILE, op.cit., p. 48. "Desde a época da Lei das XII Tábuas, diz Mainz, os principais crimes e delitos estão constituídos: Durante dez gerações o rol dos crimes públicos só foi aumentado por algumas leis que punem o peculato, ... E, talvez, o plagium. Quanto aos delitos privados, só foram conhecidos dois novos: a rapina ( actio bonorum vi raptorum) e o dano injustamente causado (damnum injuria datum). " Idem, ibidem., p. 48

13. BONFANTE, PIETRO-Histoire du Droit Romain (Storia di Diritto Romano), I, Paris, Sirey, 1928, p. 165. "La distinction du jus publicum... Et du jus privatum ... Ne pouvait être, à l'origine, qu'une distinction de sphères diverses, mais jamais de choses essenciellement diferentes”. Idem, ibidem, p. 165

14. MEIRA, SÍLVIO - Lei das XII Tábuas, $2^{a}$ ed., Rio de Janeiro, Forense, 1961, pp. 210-212.

15. MOMMSEN, TEODORO - El Derecho Penal Romano, I, tradução do alemão de Pedro Dorado Montero, Pamplona, Navarra, Jimenez Gil Editor, edição facsimilar, 1999, pp. 58-59.

16. Idem, ibidem, p. 59

17. Lei das XII Tábuas, VII, 11: Si membrum rupsit, ni cum eo pacit, talio esto: Se alguém arrancar membro de outrem, aplique-se-lhe a lei do taleão, a não ser, que haja acordo. Esse dispositivo, que prevê o talião, já marca um avanço, pois prefere a composição à vingança privada da vítima.

18. Vide GIORDANI, MÁRIO CURTIS - Direito Penal Romano, $2^{\mathrm{a}}$. Ed., Rio de Janeiro, Forense, 1987, pp.95-109; MEIRA, SÍLVIO Processo Civil Romano, $2^{\mathrm{a}}$ ed., Belém, Farangola, s/d, passim. E BURDESE, ALBERTO Manuale di Diritto Pubblico Romano, $2^{\text {a }}$. Ed., Torino, Utet, 1997, Cap. V - Diritto e Processo Criminale, pp. 225-263

19. SANTOS JUSTO, ANTONIO - Direito Privado Romano, I, $2^{\text {a }}$. Ed., Coimbra, Coimbra editora, 2003, p. 22.

20. DURKHEIM, ÉMILE, op. Cit., p. 121. Gaudemet parece discordar de DURKHEIM quando observa que "encore dans les XII Tables, qui témoignent cependant d'une laicisation déjà accusée du droit, on trouve des prescriptions d'objet religieux à coté de règles purement laiques. Les sanctions penales archaiques (sacratio, supplicium) avaient un caractère religieux et certains actes de droit ancien (confarreatio, sponsio, sacramentum) faisaient aussi appel à la religion”. GAUDEMET, JEAN - Institutions de l'Antiquité - 2. Éd, Paris, Sirey, 1982, p. 380.

21. Idem, Ibidem, p. 121

22. "O direito criminal já não ocupa todo o espaço. As regras que são sancionadas por penas e as que têm apenas sanções restitutivas são, desta vez, bem distintas umas das outras. $\mathrm{O}$ direito restitutivo desprendeu-se do direito repressivo, 
que o absorvia primitivamente; ele agora tem suas características próprias, sua constituição pessoal, sua individualidade”. DURKHEIM, ÉMILE, ibidem, p. 121. Comparando o Direito Romano com o direito hebreu, DURKHEIM acrescenta: "Não é possível enumerar todos os crimes religiosos que o Pentatteuco distingue e reprime, enquanto o direito contratual, o direito de testar, a tutela, a adoção, previstas na Lei das XII Tábuas, são completamente desconhecidas no direito hebreu". Idem, ibidem, pp. 117-119 e 447.

23. Vide PARSONS, TALCOTT - Social System, New York, Macmillan, 1968; SMELSER, NEIL J. - "Processes of Social Change", in SMELSER NEIL J.(ed) - Sociology: an Introduction, New York, John Willey \& Sons, 1967, pp. 667-728.

24. Não se podia pertencer, ao mesmo tempo, a duas fámílias, quando a filha se casava, deixava a família do pai e passava a pertencer à família do marido.

25. “A civitas era xenófoba, como, em regra, toda cidade antiga” MATOS PEIXOTO, JOSÉ CARLOS - Curso de Direito Romano, Rio de Janeiro, Haddad, 1960. P. 247

26. Entre as mais utilizadas variáveis de padrão de Parsons, para medir o grau de modernidade ou atraso das instituições estão: o universalismo versus particularismo, a especificidade versus difusão e a realização (achievement) versus condição pessoal (adscription).

27. D., 1,1,1,2, ULPIANO.

28. DURKHEIM, ÉMILE - op. Cit., p. 37

29. Idem, ibidem, p.37

30. Idem, ibidem, p. 87

31. Idem, ibidem, pp. 108-109

32. Idem, ibidem, p. 108

33. Já antes de Cristo, a distinção se firmara não só entre os jurisconsultos, mas também entre os literatos. O plural do verso de VIRGÍLIO - fas et jura sinunt - isto é, o fas e o jus permitem, não teria nenhum efeito se as palavras fossem sinônimas. Vide PINTO, AGERSON TABOSA - Direito Romano, op. Cit., p. 44 - Merece transcrita, por sua clareza e precisão, a explicação de GUARINO, citada por MOREIRAALVES, relativa ao surgimento da distinção entre jus e fas: " Primitivamente, a vontade divina se manisfestava não pelo fas (o que é lícito, pela religião, fazer) nas pelo nefas (o que não se pode fazer); posteriormente, os romanos concluíram que tudo o que não fosse nefas ( proibido fazer) seria fas (permitido fazer). O fas, portanto, era a manifestação da vontade humana, delimitada pelo nefas (exteriorização do querer dos deuses) e é da evolução do conceito de fas que vai surgir, mais tarde, jus, quando, então, fas passa a significar direito sagrado, e jus, direito profano” . MOREIRAALVES, JOSÉ CARLOS, Direito Romano, I, 5a . Ed., Rio de Janeiro, Forense, 1983, p. 91 
34. Publicum jus in sacris, in saberdotibus, in magistratibus consistunt. D. 1,1,1,2, ULPIANO.

35. Já época de CICERO, informa ROSTOVTZEFF, “Roma era ... Um grande centro de comércio e servia também como centro de troca para todo o mundo. Grandes negócios eram concluídos no forum, como, por exemplo, o suprimento de cereais para Roma e a exportação italiana de azeite e vinho" . ROSTOVTZEFF, M - História de Roma (Rome) 5a . Ed., Rio de Janeiro, Zahar, 1983, pp. 154-155.

36. CICERO, MARCUS TULIUS, De Officiis, I , 34.

37. MEIRA, SÍLVIO - Lei das XII Tábuas, op. Cit., p. 211

38. "Não há como duvidar de que o processo civil, constante das três primeiras tábuas, deve ser entendido como jus publicum. O processo é o meio de aplicação do direito pelo poder estatal. Na lei decenviral os magistrados o exerciam, embora com resquícios da justiça privada. Esses magistrados eram peças da máquina governamental. Utrapassavam já os romanos a fase da justiça privada, paulatinamente substituída pela justiça pública”. MEIRA, SÍLVIO, ibidem, p. 215.

39. DURKHEIM, ÉMILE, op. Cit., p. 65, “ El hecho ilícito o delito civil.

40. MEIRA, SÍLVIO, Lei das XII Tábuas, op. Cit., p. 211

41. IGLESIAS diz que "El Derecho Romano no conoce el delictum, como categoria general e abstracta, sino particulares delicta”, nem também a categoria dos quase-delitos, mas somente determinados quase-delitos, considerando as obrigações oriundas de uns e de outros como obrigações derivadas de atos ilícitos. IGLESIAS, JUAN - Derecho Romano: Instituciones de Derecho Privado, v. II, Barcelona, Ariel, 1953. P. 124.

42. RASCÓN, CÉSAR GARCÍA-Manual de Derecho Romano, $2^{\mathrm{a}}$ ed., Madrid, Tecnos, 1996, p. 221.

43. DANTAS, SAN TIAGO - Programa de Direito Civil, $2^{\text {a }}$. Tiragem, Rio de Janeiro, Editora Rio, 1979, p. 343

44. Idem, ibiidem, p. 348

45. Vide Digesto, 9,2; e I., 4,3

46. DANTAS, SAN TIAGO Idem, ibidem, p. 349

47. Idem, ibidem, p. 351

48. Espanha - Código Civil, Madrid, Editorial Civitas ... P. 508

49. Brasil - Código Civil Comparado, São Paulo, Saraiva, 2002, pp. 232-233. A nós nos parece que a definição do Código Civil anterior era mais precisa e completa: “Aquele que, por ação ou omissão voluntária, negligência ou imprudência, violar direito e causar dano a outrem, ainda que exclusivamente moral, comete ato ilícito. Idem, ibidem, pp. 47-48. 


\section{CRIMINAL LAW AND MODERNIZATION}

Abstract: Durkheim, one of the founders of Juridical Sociology, developed the concept that Law naturally evolves from repressive law to restitution law. It is thus questioned whether criminal law preceded civil law, as defined nowadays. Based on Rome's Lex Aquilia, modern thinkers have concluded that damnum injuria datum is the origin for tort, as understood at present, confirming Durkheim's thesis.

Keywords: Sociology. Criminal Law. Durkheim. Punishment. 